\title{
Rethinking and researching transformation in higher education: A meta-study of South African trends
}

\begin{tabular}{|c|c|}
\hline \multicolumn{2}{|c|}{$\begin{array}{l}\text { Authors: } \\
\text { Petro du Preez }{ }^{1} \\
\text { Shan Simmonds }{ }^{1} \\
\text { Anné H. Verhoef }\end{array}$} \\
\hline \multicolumn{2}{|c|}{$\begin{array}{l}\text { Affiliations: } \\
{ }^{1} \text { Faculty of Education, School } \\
\text { for Education Studies, } \\
\text { North-West University, } \\
\text { Potchefstroom Campus, } \\
\text { South Africa }\end{array}$} \\
\hline \multicolumn{2}{|c|}{$\begin{array}{l}{ }^{2} \text { Faculty of Arts, North-West } \\
\text { University, Potchefstroom } \\
\text { Campus, South Africa }\end{array}$} \\
\hline \multicolumn{2}{|c|}{$\begin{array}{l}\text { Corresponding author: } \\
\text { Anné Verhoef, } \\
\text { anne.verhoef@nwu.ac.za }\end{array}$} \\
\hline \multicolumn{2}{|c|}{$\begin{array}{l}\text { Dates: } \\
\text { Received: } 07 \text { May } 2016 \\
\text { Accepted: } 29 \text { Aug. } 2016 \\
\text { Published: } 29 \text { Sept. } 2016\end{array}$} \\
\hline \multicolumn{2}{|c|}{$\begin{array}{l}\text { How to cite this article: } \\
\text { Du Preez, P., Simmonds, S. \& } \\
\text { Verhoef, A.H., 2016, } \\
\text { 'Rethinking and researching } \\
\text { transformation in higher } \\
\text { education: A meta-study of } \\
\text { South African trends', } \\
\text { Transformation in Higher } \\
\text { Education 1(1), a2. http://dx. } \\
\text { doi.org/10.4102/the.v1i1.2 }\end{array}$} \\
\hline \multicolumn{2}{|c|}{$\begin{array}{l}\text { Copyright: } \\
\text { (C) 2016. The Authors. } \\
\text { Licensee: AOSIS. This work } \\
\text { is licensed under the } \\
\text { Creative Commons } \\
\text { Attribution License. }\end{array}$} \\
\hline \multicolumn{2}{|l|}{ Read online: } \\
\hline 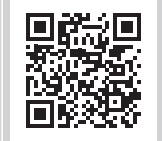 & $\begin{array}{l}\text { Scan this QR } \\
\text { code with your } \\
\text { smart phone or } \\
\text { mobile device } \\
\text { to read online. }\end{array}$ \\
\hline
\end{tabular}

Transformation is often loosely defined. We argue that the reason for this is its inherent complexity. Paradoxically, its lack of definition is an asset, which provides an opportunity to rethink and research transformation in higher education, rather than an urgent problem to be solved. In this article, the possibilities for researching and rethinking transformation are based on an exploration of transformation in higher education and the policy directives that influenced its development in South Africa. A meta-study was used to determine the national publishing trends in the South African Journal of Higher Education and the way transformation in higher education is situated in some of the articles in this journal. The population of the study comprised 1050 articles published between 2005 and 2015 in the South African Journal of Higher Education. These were analysed to determine the broad national publishing trends. Thereafter, an in-depth analysis was conducted on 30 of these articles to determine the approach to transformation in higher education and the context in which it was discussed. Based on the findings of the analysis, we recommend future directions for rethinking and researching transformation in higher education.

\section{Transform}

Transformation is often described as a complex, open-ended concept (Venter \& Tolmie 2012:1) and even dismissed as 'so vague and indistinct that it is basically an unusable term' (Venter 2015:175). The etymology of the word is derived from the Old French or Late Latin transformation (noun). Its root is the Latin verb transformare. The prefix trans meaning 'across', 'beyond', 'above', or 'bridging' is combined with formare meaning 'to form'. In the 1590s, the concept of transformation was used to mean 'undergoing a change in form'. To transform is thus to cause or undergo a change in form, nature, or appearance. Transformation can refer to processes of change in physics (a change of one element into another), mathematics (conversion of one figure into another of a similar value), linguistics (conversion of one syntactic form into another), biology (alteration of a cell), personality (change in character or appearance) and politics (ideologically driven change). The Greek term for transformation, metaschimatismos, emphasises a change in form, but includes the idea of 'remodelling, modification, and restructuring'. The noun 'transformation' is indeed complex and open-ended, but its core meaning is 'to undergo and/or cause a change of form'.

The concept 'transform' is essentially about change and evolution. It cannot be associated with rigidity because it implies constant remodelling, modification and restructuring of some sort. This adaptation could be an internal or an external process (Malabou 2008:5). When something is transformed, it could imply that it received (and internalised) its form from an outside force. However, to transform means that form is given to something external. But, crossing or bridging form through change and evolution could also be the result of the annihilation of form, that is, the destruction of form (Malabou 2008:5). Malabou (2012) writes that:

[ $n$ ]o one thinks spontaneously about a plastic art of destruction. Yet destruction too is formative. A smashed-up face is still a face, a stump a limb, a traumatized psyche remains a psyche. Destruction has its own sculpting tools. (p. 4)

This destruction that makes crossing or bridging form possible could be seen as '... a threatening detour that opens up another pathway, one that is unexpected, unpredictable, dark' (Malabou 2012:6). The concept 'transform', therefore, with its inherent ability to take form, give form and annihilate form presents infinite possibilities for crossing or bridging form (Malabou 2012:10). Seen in this way, the concept 'transform' is therefore not the result of external forces but is, in fact, programmed by the concept (transform) itself. In other words, the fuzziness of 'transform' reflects 
the inherent complexity of the concept. Rather than regarding the elusiveness of a definition as an urgent problem to be solved, it should be seen as providing a catalyst for rethinking and researching transformation in higher education.

\section{Transformation in higher education}

A brief review of the literature on the history of the transformation of higher education in South Africa indicates that attempts to understand or research this notion can be categorised into three main discourses. The first is the structural discourse which is concerned with the transition to a democratic society. The issue of equality and efficiency of the higher education system is primary in this view of transformation. The Education White Paper 3 of 1997 is the main impetus for this type of transformation. The second discourse is related to ideology. This involves broader and deeper understanding of transformation which developed mainly as a result of the 2008 Report of the Department of Higher Education. This report is based on the work of the Ministerial Committee on Transformation and Social Cohesion and the Elimination of Discrimination in Public Higher Education institutions (MCTHE). The third discourse on understanding and researching transformation is more comprehensive than the South African primary (and sometimes limited) discourse on transformation as redress of inequality (structural) and reaction to racism after apartheid (ideological). This third discourse includes various aspects concerned with transformation in South Africa (e.g. epistemology, curriculum, accessibility, equality, institutional and management structures, teaching and learning); however, it emphasises that transformation of higher education in South Africa has to be seen in the context of internationalisation. Internationalisation provokes a wide range of insights to transformation and remains an enormous factor to recognise in the ongoing debate on transformation of higher education in South Africa.

The decision to include internationalisation as a key factor in transformation in higher education should not be seen as dismissing the importance of giving due account to the unique focus and history of transformation in South Africa. As Fourie (1999:275) argues, the phenomenon of global transformation of higher education is 'an undeniable fact'. South Africa has to take account of 'the rapid transformation [higher education has undergone] throughout the world ... and [the likelihood that it is] in a period of unprecedented change' (Green \& Hayward 1997:3). Similarly, Hagstrom and Steen (1995:15) argue that the world is going through such major changes that we may be talking about a 'new epoch'. South Africa is inevitably affected by global economic, political, intellectual, technological and religious developments. The emergence of what is sometimes termed 'the new knowledge society' calls for a re-evaluation of the university system. For Venter (2015:176), the implication is that ' $k k]$ nowledge transmission and production should be pursued in dialogue with [these] global contexts'. In brief, internationalisation is not only the broader context of higher education but also one of the directions that transformation of higher education must take.
The unique history of transformation in higher education in South Africa is pinpointed by Venter (2015:176): 'In South Africa's higher education, transformation has a clear primary reference: apartheid'. Before 1994, there had been demands for internal change in South African higher education, particularly by student organisations such as the South African Students Congress (SASCO), the Pan-African Students' Organisation (PASO) and from staff associations such as the Union of Democratic University Staff Association (UDUSA) (Fourie 1999:278). However, it was only after South Africa's formal transition to democracy in 1994 that there was real impetus for change to a more open, relevant and non-discriminating higher education system. Two key policy documents were the Education White Paper 3 (South Africa, Department of Education 1997) and the National Plan for Higher Education (South Africa, Department of Education 2001). The latter outlined the framework and mechanisms for implementing and realising the policy and goals of the White Paper.

The White Paper (South Africa, Department of Education 1997:2) states that transformation of the higher education system should 'reflect the changes that are taking place in our society'. These changes can be summarised as the attempt to redress inequalities of the past as follows: Accordingly,

[t]he higher education system must be transformed to redress past inequalities, to serve a new social order, to meet pressing national needs and to respond to new realities and opportunities' and 'the framework for change, that is, the higher education system must be planned, governed and funded as a single national co-ordinated system. This will enable us to overcome the fragmentation, inequality and inefficiency which are the legacy of the past ... (South Africa, Department of Education 1997:2)

Transformation of higher education is seen as 'part of the broader process of South Africa's political, social and economic transition, which includes political democratisation, economic reconstruction and development, and redistributive social policies aimed at equity' and 'a necessity, not an option', in the South African context (South Africa, Department of Education 1997:29).

Although there was a proper emphasis on equality, efficiency and structural changes in the White Paper, the transformation related to racism was not addressed until the 2008 MCTHE Report. The MCTHE was set up after a racist incident at the University of the Free State (the so-called Reitz-sage). Its report differs from the White Paper in that it does not limit attention to transformation in higher education to narrow 'institutional compliance' (structural, efficiency and equality), but broadens transformation to address all aspects of university life. According to Francis and Hemson (2010:876), one 'implication is that we need research that explores discrimination with a view to interrogating the whole system of higher education'. The MCTHE Report (South Africa, Department of Education 2008:11) clearly says: '... the transformation agenda includes the necessity to examine the underlying assumptions and practices that underpin the academic and intellectual projects pertaining to learning, teaching and research'. 
The definition of transformation of higher education in the South African context was largely framed by these two reports. The White Paper (1997) emphasised transformation of higher education in terms of sociological relationships, structural changes, efficiency, mergers of institutions, the forming of one national higher education system and institutional compliance in terms of redressing inequality (accessibility, equality of race and gender, demographical representation of staff and students of society). This kind of transformation can be summarised as 'structural transformation' (Soudien 2010:882). Examples of research in this regard include Fourie's (1999), 'Institutional transformation at South African universities: Implications for academic staff', Bitzer and Bezuidenhout's (2001), 'Transformation' as a problematic concept in the realm of higher education in South Africa', Waghid's (2002) 'Knowledge production and higher education transformation in South Africa: Towards reflexivity in university teaching, research and community service', and Van Wyk's (2005) 'Performativity in higher education transformation in South Africa'. Fourie (1999) focuses particularly on institutional transformation through democratising the governance structures of institutions and the implications of the process for academic staff. Her article also addresses broader aspects of transformation (e.g. internationalisation) and seeks a deeper understanding of transformation that will be discussed later. Bitzer and Bezuidenhout (2001:39) emphasise that transformation should be seen as 'the opportunity to realise the vision of quality education for all who are capable thereof at our institutions'. Waghid (2002:457) asks how 'the emergent shift in knowledge production can transform higher education in South Africa to the extent that it becomes socially more relevant' and emphasises the importance of community service by universities. Transformation is not understood here as a goal in itself, but to improve and create a more just and more equitable society (Waghid 2002:458). Van Wyk (2005) warns of the likely sham that could result if 'structural transformation' is reduced to its narrow sense (e.g. performativity or efficiency). He argues for 'deep transformation', which takes into account African notions of Ubuntu and community, such as forgiveness, recognition, humanness, respect and politeness (Van Wyk 2005:17). This emphasis on human dignity is closely linked to the second discourse, and broader and deeper understanding of transformation of higher education.

The MCTHE Report (2008) marks a shift from research on structural transformation to a broader ideological discourse of transformation. Soudien (2010:876) states that this ideological discourse addresses beliefs and assumptions about transformation of higher education. This discourse explores discrimination and racism in great detail. Transformation of higher education includes the following issues: epistemological change; discrimination and exclusions in terms of religion, ethnicity, sexual orientation, class and language; Africanisation or decolonisation of the curriculum; beliefs, attitudes, values and commitments of the whole system; power; diversity; and intellectual justice. The shift to this ideological discourse on transformation of higher education is evident in research such as the collection of essays compiled by Venter and Tolmie, 'Transforming theological knowledge: Essay on theology and the university after apartheid' (2012), and in the special issue on transformation in the South African Journal of Higher Education (2010). In Venter and Tolmie's (2012:2) book, various authors grapple with epistemological transformation and argue that 'deep conversations about the nature purpose and politics of transformation have been neglected'. The South African Journal of Higher Education's special issue examines the underlying assumptions and practices which underpin higher education in South Africa (Francis \& Hemson 2010:875). Soudien, for example, argues that 'racism continues to be deeply present within the system, structurally and ideologically' (2010:893) and that universities 'harbour, nurture and reproduce particular notions of society, the institution, the self and the other' (2010:890). To develop a deep understanding of the ideological phenomenon of racism in higher education - which is malleable and fluid - is part of the nature and challenge of transformation of higher education.

Taking account of the three main discourses that scholars employ in engaging with transformation in higher education, this article asks the following question: 'What are the possible future directions of rethinking and researching transformation in higher education?' Next, how the empirical research unfolded is discussed.

\section{Meta-study research}

There has been an increasing trend towards meta-designs (e.g. meta-analysis, meta-sociology, meta-ethnography, metasynthesis and meta-studies) in social sciences since the 1970s. In the health sciences, meta-designs have been widely used to incorporate the wide array of knowledge developed through research and thus strengthen the validity and reliability needed for trustworthy, practical application (Paterson et al. 2001; Pope, Mays \& Popay 2007). The rise of the knowledge economy too has created a need for research to be synthesised and packaged in less relativist ways so that more trustworthy generalisations can be made (Pope et al. 2007:3). The criticism that researchers constantly reinvent the wheel when conducting research instead of capitalising on existing research has highlighted the need for meta-designs (Paterson et al. 2001:4).

More recently, education research has also acknowledged the value of meta-study research (Du Preez \& Simmonds 2014; Simmonds \& Du Preez 2014). Paterson et al. (2001:1) define a meta-study as 'a research approach involving analysis of the theory, methods, and findings of qualitative research and the synthesis of these insights into new ways of thinking about phenomena'. A meta-study is dynamic, iterative and can engage with diverse evidence types and therefore requires tailored methods and approaches based on the review questions posed (Dixon-Woods et al. 2005:49; Pope et al. 2007:12). Although meta-studies will differ from each other, 
an important starting point for designing and conducting a meta-study includes the following questions (Paterson et al. 2001; Pope et al. 2007):

What is the purpose of the meta-study? Is it to contribute to knowledge development in the field, or for policy decisionmaking processes? Is it to synthesise findings, or to determine trends in a particular cluster of studies?

What needs to be analysed and synthesised through the metastudy, and why? Is it the topics, theories, methods and findings? What is anticipated through the meta-study?

The purpose of our meta-study was to contribute to knowledge development by identifying trends in the articles published in the journal, South African Journal of Higher Education. This journal's aim is to provide institutions of higher education and professional readers with scholarly information on major innovations in higher education, research projects and trends. We were not interested in aggregating the actual findings in the articles or in comparing the articles (Pope et al. 2007:16). In this sense, we were concerned with interpreting these articles within the context of our two review questions (Pope et al. 2007:17): (1) What are the national publishing trends in the South African Journal of Higher Education? (2) Based on a refined selection of articles published in the South African Journal of Higher Education, how and in what contexts is transformation in higher education discussed?

Drawing on the groundwork laid by Paterson et al. (2001) and Pope et al. (2007), we developed our own process of conducting meta-studies. Figure 1 schematically represents this process.

\section{Level 1: Design and organisation}

Our meta-study began with formulating the two exploratory review questions stated above to enable us to take account of all the complicated dimensions of the problem. We then developed working procedures to establish initial inclusion and exclusion criteria so that sampling could be done and the corpus of documents (articles) could be selected. This is extremely important for the reliability and trustworthiness of inferences made towards the end of a meta-study (Pope et al. 2007). These particular articles were the focus because they were published by the South African Journal of Higher Education between 2005 and 2015 and provide an indication of the national publishing trends in higher education over the past 11 years. The South African Journal of Higher Education's website, which we accessed via the Sabinet data base on our university library website, was used as sample frame to retrieve the articles. A population of $N=1050$ articles in portable document format (pdf) format (excluding tributes, calls for papers and certain editorials) was analysed.

\section{Level 2: Identifying national publishing trends in higher education}

A descriptive analysis was performed of the entire population of articles $(N=1050)$. This involved analysing the titles and

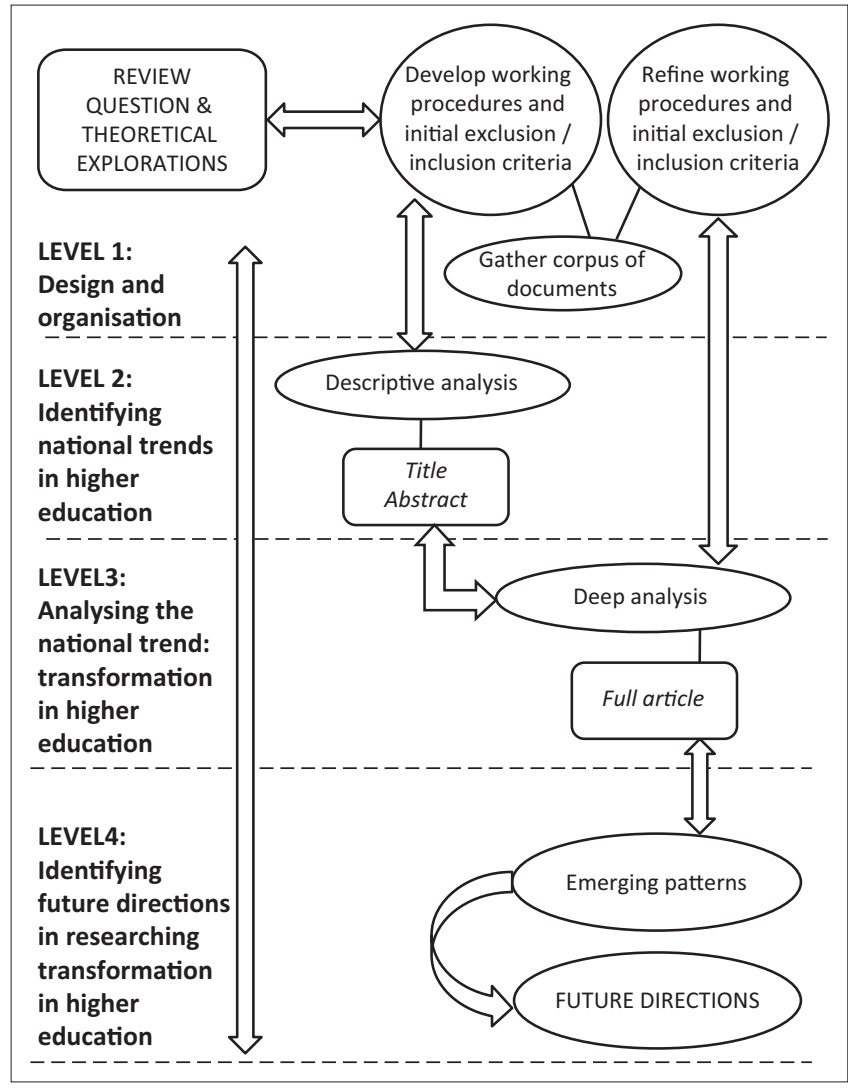

FIGURE 1: A schematic representation of the critical meta-study process.

abstracts of each article to determine the higher education topic put forward. Initially, articles were categorised into the three broad strategic priorities subscribed to by most South African higher education institutions: teaching-learning, research and community engagement. However, because of the scope of topics covered by the articles, three additional categories emerged: higher education as context, vocational education and miscellaneous (outside the higher education context). Table 1 demonstrates these trends and their subtrends.

From the findings, it is evident that national publishing trends in higher education from most to least prominent are higher education as context, teaching-learning, research, miscellaneous (outside the higher education context), community engagement and vocational education.

\section{Level 3: Analysing the national publishing trend - transformation in higher education}

Level 3 required further refinement of criteria used to include or exclude articles that explicitly used the word 'transformation' in their title. Of the population $(N=1050)$, a sample of $n=30$ articles (3\%) used 'transformation', 'transformational', 'transformative' or 'transforming' in their titles. This sample (3\%) featured as a subtrend in higher education as context in level 2. In-depth analysis of the discourse of the entire articles in this sample was undertaken to determine precisely how and in what contexts transformation in higher education was discussed. 
TABLE 1: A breakdown of the population and emerging trends.

\begin{tabular}{|c|c|c|c|c|}
\hline Trends & Number of articles per trend & $\begin{array}{l}\text { Percentage of trends in total } \\
\text { population }(N=1050)\end{array}$ & Subtrends & Number of articles \\
\hline \multirow[t]{11}{*}{ Teaching-learning } & 373 & 35.5 & Curriculum matters/programmes & 63 \\
\hline & & & Teaching methods & 40 \\
\hline & & & Learning approaches & 57 \\
\hline & & & Assessment & 26 \\
\hline & & & Technology & 48 \\
\hline & & & Teaching-learning of students & 19 \\
\hline & & & Teaching-learning theories & 40 \\
\hline & & & Academic literacy/reading/writing & 33 \\
\hline & & & $\begin{array}{l}\text { Africanisation/African episteme/Indigenous } \\
\text { knowledge systems }\end{array}$ & 26 \\
\hline & & & $\begin{array}{l}\text { Teaching-learning materials/textbooks/ } \\
\text { teaching-learning study materials }\end{array}$ & 5 \\
\hline & & & Quality of/in teaching-learning & 16 \\
\hline \multirow[t]{6}{*}{ Research } & 136 & 13 & Postgraduate studies & 89 \\
\hline & & & Research productivity & 9 \\
\hline & & & Scholarly journal publication & 5 \\
\hline & & & Quality in/of research & 5 \\
\hline & & & Theorising research & 12 \\
\hline & & & Professoriate & 1 \\
\hline Community engagement & 20 & 2 & Interface of university/government/community & 20 \\
\hline \multirow[t]{20}{*}{ Higher education as context } & 484 & 46 & Administration/governance & 21 \\
\hline & & & Access/epistemological access & 19 \\
\hline & & & Academic success/performance/failure & 50 \\
\hline & & & Race & 21 \\
\hline & & & Gender & 4 \\
\hline & & & Internationalisation & 17 \\
\hline & & & Academic staff development & 15 \\
\hline & & & National trends & 28 \\
\hline & & & HIV/AIDS & 5 \\
\hline & & & Students & 37 \\
\hline & & & Graduate attributes/alumni & 8 \\
\hline & & & Finances & 11 \\
\hline & & & Transformation & 30 \\
\hline & & & Quality in/of higher education & 22 \\
\hline & & & Language policy & 4 \\
\hline & & & Career development & 30 \\
\hline & & & Counselling & 10 \\
\hline & & & Women academics/black women academics & 15 \\
\hline & & & Knowledge production & 23 \\
\hline & & & Teacher education/student-teachers & 41 \\
\hline Vocational education & 5 & 0.5 & General/skills management/marketing of & 5 \\
\hline $\begin{array}{l}\text { Miscellaneous (outside the higher } \\
\text { education context) }\end{array}$ & 32 & 3 & School/teachers/learners & 32 \\
\hline
\end{tabular}

Four main patterns emerged in the findings: transformation through curriculum, transformation through structures, transformation through redressing equity and transformation through access.

\section{Transformation through curriculum}

In the sample, 12 articles positioned transformation in the higher education curriculum. In this instance, curriculum pertained to teaching-learning dimensions such as learning theories, teaching strategies, teaching-learning quality measures, as well as the integration of technology. The articles in this pattern also engaged with curriculum in reform in the sense that a curriculum is flexible and constantly evolving in the higher education landscape. Aspects such as the professional development of academics and student experiences were also discoursed as key ways in which curricular reforms are received or challenged. In addition, particular programmes, such as teacher education, were used to argue for transformation through curriculum.

\section{Transformation through structures}

Nine of the articles in the sample, the next biggest group, related transformation to structures in higher education. In these articles, there were three key aspects. The first aspect concerned ideas, practices and the role of structure in nation-building. The second aspect pertained to broader 
national trends such as higher education policy evaluation and reform, as well as the government policies and legislation on transformation that inform and shape the higher education landscape in South Africa. The third aspect is related to the structures within institutions that influence transformation. These structures are institutional culture underpinned by hegemonic forces shaping institutional transformation (with whom, for whom and by whom), the management and leadership of an institution as sceptics or advocates for transformation, transformation emanating from institutional mergers and the effects of academic staff performativity.

\section{Transformation through redressing equity}

Six of the articles in the sample viewed transformation as redressing equity in higher education and discussed the way national equity debates inform it. The notion of equity in terms of race featured most strongly. Race as a national priority in government policy, the critical engagement of the concept 'race' and how these arguments could inform institutional transformation as well as reimagining future academic institutions, featured. These articles viewed equity redress as embedded in race, gender and class. These articles referred specifically to the inclusion and exclusion of academic staff within institutions, including recruitment policies. Transformation was thus viewed as occurring through employment equity, the reconfiguration of power structures and alternative ways of conceptualising the diversity profiles of the staff of an institution.

\section{Transformation through access}

Three of the articles, the smallest group in the sample, argued that access is a prerequisite for successful transformation in higher education. Framed as access for success or access to enable the transformation agenda, these articles contend that access is shaped by contextual and personal forces. In these arguments, specific reference was made to the access of black women academics as well as the access of students who are underprepared for tertiary education. These students bring with them linguistic barriers and literacy challenges (reading and writing).

The patterns that emerged from the level 3 in-depth analysis can be regarded as four faces or dimensions of transformation in higher education. These served as critical points for theoretical engagement aimed at identifying possible future directions for rethinking and researching transformation in higher education should take.

\section{Level 4: Patterns emerging from levels 2 and 3 analysis}

In the following, we discuss three main patterns that emerged from levels 2 and 3 analysis: community engagement, teaching-learning and policy imperatives.

\section{Community engagement}

A small minority of 20 published articles concerned themselves with community engagement as a national priority (level 2). It should be noted that community engagement did not feature at all in the analysis of published articles on transformation in higher education (level 3). This was a significant finding given the emphasis community engagement enjoys, along with teaching-learning and research, in higher education (South Africa, Department of Education 1997). Overall, the main findings indicate that the emphasis falls on teaching-learning.

\section{Teaching-learning}

The subtrend technology featured prominently (48 published articles) in the national trend in teaching-learning. The subtrend that featured least well included articles published on teaching-learning support materials (five articles). The reason for this could be the shift in higher education institutions' visions towards eLearning platforms and including approaches such as self-directed learning and blended learning technology in teaching-learning.

\section{Policy imperatives}

Many of the findings were related to policy matters. This could directly and indirectly be linked to the initial policy changes suggested through the White Paper of 1997, followed by the Report of the MCTHE of 2008. Policy changes that concerned curriculum and programme matters, access for success as well as institutional culture and management featured strongly. These are elaborated here.

Sixty-three articles dealt with issues related to curriculum and programme matters. This could be understood in light of the Education White Paper of 1997 that proposed ongoing national curriculum and programme audits for accreditation purposes be conducted in higher education institutions. This led to a greater interest in research on curriculum and programme issues. The focus on epistemological transformation proposed in the Report of the MCTHE (2008) encouraged research on curriculum epistemology. These developments also included a shift towards research about the epistemological access through curricula in terms of Africanisation and Indigenous African Knowledge Systems.

Another pertinent finding relates to access for success. The access for success pattern broadened access from a focus on providing admission to higher education institutions to a focus on redressing inequality. Access for success focuses not merely on giving students access to institutions and providing opportunities for staff, but also on offering support in all aspects of academia to increase the possibility of success. It is therefore no surprise that 50 articles were published on matters related to academic success, performance and failure and 15 articles focused on (black) women academics. Equity of race, gender and class frequently featured in articles that elaborated on issues pertaining to redress. This was done not only in the context of structural transformation, which often focuses on providing access for the previously disadvantaged, 
especially in the context of ideological transformation. The 1997 White Paper and the 2008 MCTHE Report recommended an increase in the number of postgraduate degrees (particularly that a greater percentage of academic staff members hold a doctoral degree). We found 89 articles that addressed the topic of postgraduate studies.

A further policy imperative was transformation of institutional culture and management approaches. This is closely related to the 1997 White Paper that urged structural change in the culture and management styles of higher education institutions so that they too could become part of the broader process of political, social and economic transition in South Africa. Seventy-three articles provided evidence of the constant emphasis on institutional culture and management approaches in higher education contexts.

Based on the patterns that emerged from levels 2 and 3 analyses, it became evident that the national publishing trends gave close attention to the structural and ideological dimensions shaping transformation. However, greater attention needs to be given to what this article has termed the third discourse shaping transformation, nationally and internationally.

\section{Conclusion}

\section{Future directions}

The articles on transformation published in the South African Journal of Higher Education mainly reflect national policy trends. This has been demonstrated when we identified national publishing trends in higher education (level 2) and when we analysed the national publishing trends concerning transformation in higher education (level 3). What we deem crucial for future research in higher education are the following: firstly, we recommend greater attention be given to the internationalisation debates informing the higher education context in order to broaden the discourse on transformation and encourage the rethinking thereof. The meta-study revealed that little research has been conducted about the internationalisation discourse in the South African context, despite the fact that our literature review gives evidence of the increasing attention placed on internationalisation discourses and transformation in higher education internationally. Secondly, scholarship on rethinking and researching transformation in higher education should extend beyond education. At present, articles published in the South African Journal of Higher Education emanate almost exclusively from the field of education, despite the fact that the journal's scope calls for interdisciplinary contributions. This finding is probably the result of the fact that the journal has historically been classified in the education realm. Finally, transformation could be approached as a fluid, open-ended construct that is inherently complex. This complexity should be embraced when rethinking and researching transformation in higher education. One way in which this fluidity, openendedness and inherent complexity could be conceptualised is by researching and rethinking the dynamic internal and external forces that lead to higher education receiving form, giving form and annihilating form (Malabou 2008; 2012).
Such research might elicit divergent outcomes and shed light on whether the fluid, open-ended nature of transformation is in fact positive or detrimental to higher education. With these initial ideas in mind, we anticipate that future research about transformation in higher education will pursue some of the findings and shortcomings identified in this article.

\section{Acknowledgements Competing interests}

The authors declare that they have no financial or personal relationships which may have inappropriately influenced them in writing this article.

\section{Authors' contributions}

P.d.P., S.S. and A.H.V. contributed equally to the research and writing of this article.

\section{References}

Bitzer, E.M. \& Bezuidenhout, S.M., 2001, “'Transformation” as a problematic concept in the realm of higher education in South Africa', Journal for Humanities 41(1), 33-40.

Dixon-Woods, M., Agarwal, S., Jones, D., Young, B. \& Sutton, A., 2005, 'Synthesising qualitative and quantitative evidence: A review of possible methods', Journal of Health Services Research \& Policy 10(1), 45-53. http://dx.doi.org/10.1258/ 1355819052801804

Du Preez, P. \& Simmonds, S., 2014, 'Curriculum, curriculum development, curriculum studies? Problematising theoretical ambiguities in doctoral theses in the education field', South African Journal of Education 34(2), 1-14. http://dx.doi. org/10.15700/201412071140

Fourie, M., 1999, 'Institutional transformation at South African universities: Implications for academic staff', Higher Education 38, 275-290. http://dx.doi. org/10.1023/A:1003768229291

Francis, D. \& Hemson, C., 2010, 'Initiating debate: South African Journal of Higher Education issue on transformation', South African Journal of Higher Education 24(6), 875-880.

Green, M.F. \& Hayward, F.M., 1997, Transforming higher education: Views from leaders around the world, Phoenix, Oryx Press.

Hagstrom, S. \& Steen, A., 1995, 'The changing role of the university', keynote speech presented at the Joint Colloquium on the University in Africa in the 1990s and beyond, National University of Lesotho, Roma, Lesotho, January 16-20, 1995, viewed from https://searchworks.stanford.edu/view/5093509

Malabou, C., 2008, What should we do with our brain?, Fordham University Press, New York.

Malabou, C., 2012, The ontology of the accident: An essay on destructive plasticity, Polity Press, Cambridge.

Paterson, B., Thorne, S., Canam, C. \& Jillings, C., 2001, Meta-study of qualitative health research: A practical guide to meta-analysis and meta-synthesis, Sage, Thousand Oaks, CA.

Pope, C., Mays, N. \& Popay, J., 2007, Synthesizing qualitative and quantitative health evidence: A guide to methods, Open University Press, Maidenhead.

Simmonds, S. \& Du Preez, P., 2014, 'The centrality of the research question for locating $\mathrm{PhD}$ studies in the global knowledge society', South African Journal of Higher Education 28(5), 1606-1623.

Soudien, C., 2010, 'Grasping the nettle? South African Higher education and its transformative imperatives', South African Journal of Higher Education 24(5), 881-896.

South Africa, Department of Education, 1997, Education White Paper 3: A programme for the transformation of higher education, Government Gazette, vol. 390, no. 18515, Government Printers, Pretoria.

South Africa, Department of Education, 2001, National Plan for Higher Education (NPHE), Department of Education, Pretoria.

South Africa, Department of Education, 2008, The report of the Ministerial Committee into Transformation in Higher Education (MCTHE), Department of Education, Pretoria.

Van Wyk, B., 2005, 'Performativity in higher education transformation in South Africa', South African Journal of Higher Education 19(1), 5-19.

Venter, R., 2015, 'Transformation, theology and the public university in South Africa', Acta Theologica 35(2), 173-203.

Venter, R. \& Tolmie, F., 2012, Transforming theological knowledge: Essay on theology and the university after apartheid, Sun Press, Bloemfontein.

Waghid, Y., 2002, 'Knowledge production and higher education transformation in South Africa: Towards reflexivity in university teaching, research and community service', Higher Education 43, 457-488. http://dx.doi.org/10.1023/A:1015211718131 